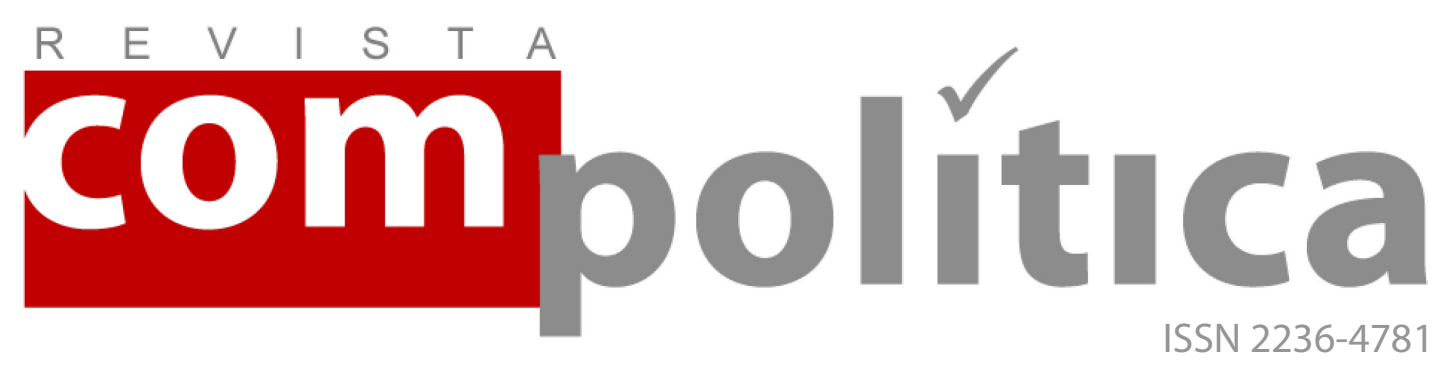

SANTOS NEVES, Manuela Lopes Coordenadora do curso de Comunicação Social da Faculdade Novo Milênio (2008-2011). Jornalista e Mestre em Ciência da Informação IBICT/UFRJ. <manuela_Isn@yahoo.com.br>

\title{
A técnica de grupo de discussão em pesquisa eleitoral: um projeto experimental
}

RESUMO

O artigo discorre sobre a aplicação do método de grupo de discussão na pesquisa eleitoral e sua contribuição para o planejamento estratégico de campanhas. A abordagem é metodológica e a análise se deu sobre a natureza das informações que este tipo de pesquisa pode proporcionar. Para tanto, partimos de uma pesquisa experimental realizada para atender à campanha de uma candidata à reeleição à Câmara dos Deputados pelo estado do Espírito Santo

Palavras-chave: marketing político; pesquisa qualitativa; grupo de discussão e campanha eleitoral.

ABSTRACT

The article is about the application of focus group method in electoral research and its contribution to the strategic planning of campaigns. The methodological approach and analysis were based on the nature of information that this kind of research may provide. The starting point was an experimental research conducted by the campaign of a re-election candidate to the House of Representatives of the state of Espírito Santo.

Keywords: political marketing, qualitative research, focus group, campaigns. 


\section{A técnica de grupo de discussão em pesquisa eleitoral: um projeto experi- mental}

\section{[The focus group technique in electoral research - an experimental project]}

SANTOS NEVES, Manuela Lopes

O

foco deste artigo é a aplicação da metodologia da pesquisa qualitativa com emprego da técnica de grupo de discussão (ou grupo focal) e sua utilização no planejamento de marketing para fins eleitorais. Buscamos aqui compreender como se fundamentam as informações que são reveladas pelos sujeitos envolvidos na dinâmica própria das pesquisas qualitativas e como estas informações podem contribuir para as estratégias das campanhas político-eleitorais. A abordagem dada aqui é, sobretudo, metodológica e a análise se deu sobre a natureza das informações que este tipo de pesquisa pode proporcionar.

Ao contrário das pesquisas quantitativas, as pesquisas qualitativas não têm caráter representativo, uma vez que o seu interesse não é a representatividade coletiva, mas sim os valores e raciocínios que são referência de um grupo em particular. Nas técnicas de entrevistas próprias da pesquisa qualitativa, o que se pretende é perceber como e em que as opiniões e os pontos de vistas dos indivíduos se formam e se fundamentam; o que e quem influencia suas opiniões; como estas se relacionam com o mundo da vida de cada um. O que se quer com sua aplicação é principalmente compreender as razões que fundamentam a opinião de indivíduos em relação ao tema posto em questão. Neste sentido, pessoas deixam de ser um dado meramente estatístico e passam a ser um sujeito social, que traz na sua fala sua experiência enquanto indivíduo inserido em sociedade. A visão do tema pesquisado se dá pela perspectiva do entrevistado.

Este artigo parte do princípio de que os especialistas em comunicação política precisam de mais do que dados quantitativos para traçar as estratégias de campanha, avaliá-las e alterá-las, se necessário. Vale lembrar que a campanha política é a instância organizadora das informações, fornecendo ao eleitor dados sobre os 
candidatos e seus respectivos adversários. "É no seu decorrer que as imagens, agendas e propostas políticas são construídas e desconstruídas" (TELLES, Helcimara, 2008, p.2).

Adotando esta postura, foi realizada uma pesquisa, em caráter experimental, com o emprego da técnica de grupo de discussão, tendo em vista a campanha eleitoral para deputado federal no estado do Espírito Santo, no ano de 2010. O objetivo principal da pesquisa foi testar a operacionalidade do grupo de discussão, a natureza da informação que é possível extrair na aplicação da técnica de entrevista em que prevalece o debate e a troca de ideias e impressões entre seus participantes. A pesquisa foi realizada no início do período eleitoral tendo como foco a campanha à reeleição da deputada federal Iriny Lopes (PT-ES), que concorria a um terceiro mandato à Câmara Federal. $\mathrm{O}$ que se pretendeu foi conhecer a opinião de um grupo de eleitores acerca do cenário político no contexto da disputa eleitoral de 2010 e a percepção da imagem e da atuação parlamentar de um candidato que buscava renovar seu mandato no legislativo federal. A partir dos resultados obtidos, foi possível discorrer sobre a aplicação da metodologia qualitativa de grupo de discussão e as contribuições possíveis ao planejamento estratégico das campanhas eleitorais.

Como se tratou de uma pesquisa experimental de nível acadêmico, como parte do aprendizado prático de alunos da disciplina "Pesquisa em Comunicação e Análise de Mercado", do curso de Comunicação Social (Faculdade Novo Milênio de Vila Velha, Espírito Santo), em que só seria possível a realização de uma única dinâmica de grupo, devido à limitação de tempo em função do calendário acadêmico, tomou-se a liberdade de constituir-se o grupo possível. Mesmo assim, buscou-se atender a pelo menos um critério de seleção dos participantes. Era importante que os selecionados tivessem uma aproximação com assuntos da pauta da deputada, para verificar em que medida seu desempenho repercute, ou não, sobre um grupo de eleitores que de alguma forma poderiam formar aquilo que no marketing é denominado o mercado eleitoral do candidato. Esta era então uma questão que deveria ser abordada no sentido de oferecer informações que fossem úteis aos objetivos estratégicos próprios do Marketing Eleitoral no que diz respeito à avaliação da imagem e ao desempenho de um candidato à reeleição. Assim, importou tanto a observação da aplicação da técnica de grupo de discussão, como a obtenção de resultados satisfatórios para fins do planejamento de marketing da campanha.

Tendo em vista o que foi posto acima, uma única reunião foi realizada, em 10 de julho de 2010, com o intuito de testar o método e 
sua aplicação técnica, numa didática em que o roteiro de perguntas foi submetido a uma avaliação inicial numa dinâmica real.

\section{Pesquisa qualitativa e marketing eleitoral}

É comum para quem não tem familiaridade com o conceito de marketing, identificar o termo com ações de promoção. Não deixa de haver um fundo de verdade nesta impressão inicial, uma vez que entre as atribuições do Marketing está a de realizar ações que promovam um serviço ou produto. o que os pouco familiarizados desconhecem é que para estabelecer as ações que serão empregadas no esforço de promoção, é necessário antes pensá-las e planejá-las com foco nos objetivos que se quer alcançar. Essa é uma regra que vale para qualquer das aplicações do Marketing, seja comercial, institucional, social, político ou eleitoral, pois, para todas elas, o objetivo a alcançar é que o produto ou serviço oferecido tenha o melhor desempenho possível junto ao público-alvo em um mercado potencial.

Aplicando esta regra ao marketing comercial, podemos admitir que o objetivo do planejamento seja definir ações que atinjam um determinado público consumidor participante de um mercado onde o produto ou serviço é oferecido. Para tal, será necessário planejar e executar "todos os aspectos de um produto ou serviço em função do consumidor, visando sempre maximizar o consumo (...) resultando em lucros contínuos (...)" (PINHO, 2001, p.23).

O planejamento de marketing evidentemente antecede a execução das ações. É necessário antes defina-las e planejá-las. Para tanto, será preciso ter conhecimento da realidade do produto, do mercado e da concorrência. Esse conhecimento vai permitir posicionar melhor o produto ou serviço diante de um público-alvo e de um mercado que também devem ser conhecidos. Essa é a etapa do planejamento que requer informação; requer pesquisa. É a partir dela que as estratégias mercadológicas poderão ser traçadas.

Compreendendo o marketing eleitoral como a aplicação das técnicas mercadológicas ao processo de disputa por cargos eletivos, como posto por Vaz (2003), podemos admitir que seu objetivo seja tornar o candidato, que ocupa o lugar do produto ou serviço do marketing comercial, aceitável para um maior número de eleitores (consumidores) e, assim viabilizar sua eleição (algo próximo à ideia de lucro no marketing comercial). 
Assim, uma das necessidades do planejamento de uma campanha será conhecer o eleitor (público-alvo), o mercado (no caso, eleitoral) e a concorrência de outros candidatos ao mesmo cargo eletivo e/ou das alianças partidárias. O conhecimento de tais questões poderá ser revelado com aplicação de dois métodos de pesquisa, o quantitativo e o qualitativo, de acordo com a natureza da informação que se quer obter. Após esta etapa, as estratégias da campanha eleitoral poderão ser melhor definidas.

As técnicas de investigação qualitativa aplicadas ao marketing político-eleitoral auxiliam o pesquisador no entendimento do comportamento das pessoas nas formas de participação política, no processo decisório do voto e na formação e difusão do pensamento político (VEIGA; GONDIM, 2001).

A pesquisa de marketing é (...) um conjunto de técnicas e procedimentos que tem por objetivo avaliar aspectos psicológicos do eleitorado visando embasar estratégias para aumentar a aceitação do candidato junto à população. Basicamente centra: i) na imagem dos candidatos, dos partidos e dos adversários, ii) no aspectos psicológicos dos eleitores e, por fim, iii) no acompanhamento de todo o processo eleitoral, intervindo de modo ativo conforme os objetivos pretendidos (FIGUEIREDO, 2000, apud VEIGA; GONDIM, 2001, p.2).

\section{Os fundamentos da informação}

O termo "qualitativo" que classifica as pesquisas com base em entrevista com questões abertas está relacionado tanto ao método de coleta como à natureza da informação que a técnica empregada permite obter. Nas técnicas de entrevistas (individuais ou grupais) a abordagem é interlocutória, numa dinâmica de conversação, onde a informação obtida é fundamentada e valorada pela explicação, exemplificação ou justificativa que a acompanha. A informação é revelada no processo de diálogo entre dois ou mais interlocutores.

Toda pesquisa com entrevistas é um processo social, uma interação ou um empreendimento cooperativo, em que as palavras são o meio principal de troca. [As entrevista são] uma interação, uma troca de ideias e significados, em que várias realidades e percepções são exploradas e desenvolvidas (GASKELL, 2002, p.73).

A entrevista aberta permite que as pessoas se expressem de forma ampla e livre, o que possibilita ao pesquisador conhecer o significado que elas dão às palavras, como produzem conceitos que embasam e dão sentido às suas opiniões. É possível compreender ainda como as 
opiniões expressas se relacionam com a realidade de vida de cada um, seus interesses, demandas, valores e motivações. São revelações baseadas no conhecimento prático da vida de cada um, ilustradas por narrativas, lembranças e experiências que os entrevistados relatam quando querem explicar seus pontos de vista.

Ao buscar a informação a partir da fala do outro, a pesquisa qualitativa considera o indivíduo como um produto do meio social, pois está implicado nas estruturas que conformam sociedades, onde a vida cotidiana deve ser entendida como o espaço da reprodução social. E essa vivência compõe "o estoque de conhecimento de que cada um dispõe para interagir com o mundo, interpretá-lo, tomar decisões e ajustar-se a ele" (VEIGA; GONDIM, 2001, p.5).

$\mathrm{Na}$ tensão entre o indivíduo e a sociedade, entre processos de construção social da subjetividade e de construção refratada do social pelos indivíduos, fica claro que estes últimos não se inserem num todo de uma só vez, mas através de instâncias intermediárias, mediadoras (BARROS FILHO; THORNTON, 2002, p.260)

No contexto da campanha político-eleitoral, tais mediações, ou intermediações, devem ser esclarecidas para que se possa conhecer a maneira como a política se desenvolve dentro desse processo de interação e de socialização, enfim, de influências a que o eleitor está sujeito.

\section{A entrevista como técnica qualitativa}

Os métodos qualitativos com emprego de técnicas de entrevistas mais conhecidos são a entrevista individual e os grupos de discussão. Na primeira, a conversação se dá entre duas pessoas, o pesquisador e o entrevistado. Cabe ao pesquisador conduzir a conversa com foco nos objetivos da pesquisa, buscando a informação que é fornecida pela visão ou opinião que o entrevistado (ou entrevistados, uma vez que a entrevista individual pode ser aplicada a mais de uma pessoa separadamente) tem do tema em questão.

Nos grupos de discussão, as informações são reveladas na interação entre um grupo de pessoas, onde importam tanto as opiniões e os pontos de vistas individuais como os consensos obtidos na discussão. Assim é possível observar também, como dado da pesquisa, o jogo de influências que se estabelece entre os participantes. A riqueza da técnica está no fato de que as informações são colhidas nas palavras 
ditas, nos pontos de vistas expressados e nos diálogos estabelecidos na concordância ou discordância de opiniões.

IV.

\section{Procedimentos da pesquisa}

Definido o objetivo da pesquisa, os primeiros procedimentos para a sua aplicação trataram da elaboração do roteiro de perguntas, que vai guiara conversação, e a seleção dos participantes, etapa do planejamento da pesquisa que corresponde a definir o que se quer saber e a quem perguntar. Em geral, parte-se daquilo que se quer saber para só então iniciar a seleção dos participantes, pois os critérios para tal escolha dependerá dos assuntos que serão explorados na pesquisa.

\section{V.1 A construção do roteiro}

A construção de um bom roteiro de entrevista é um dos pontos fundamentais que vão garantir que os resultados obtidos serão satisfatórios aos objetivos da pesquisa. 0 roteiro deve obedecer a uma lógica que vai do geral ao específico, sendo construído em forma de tópicos (ou temas), que são referências (ou guias) para as questões que serão colocadas em discussão, de forma que atenda aos objetivos da pesquisa. Este esquema, ou tópico-guia, se constitui dos objetivos secundários da pesquisa, que indicam o caminho a percorrer para alcançar o objetivo principal. Sua função, como o nome sugere, é de servir de guia ao pesquisador, "fornecendo uma progressão lógica e plausível através dos temas em foco" (Gaskell, 2005, p.67). Em geral, nos relatórios finais dos grupos de discussão, os tópicos-guia formam os títulos de parágrafos, que organizam com mais clareza e coerência a apresentação dos resultados da pesquisa.

No caso da pesquisa empreendida aqui, a construção do roteiro se apoiou na descrição de VEIGA e GONDIM (2001, p. 4) para os objetivos da pesquisa de marketing eleitoral, que são: compreender a percepção do eleitor acerca do quadro político, apontando aspectos positivos e negativos; conhecer suas demandas e frustrações; identificar suas expectativas com relação à solução dos problemas sociais; avaliar a imagem dos candidatos e as razões para votar ou não nos mesmos e; aferir a avaliação de propostas ou plataformas de atuação parlamentar.

De acordo com estas orientações, o roteiro foi construído sobre os seguintes tópicos: 
Tópico 1 - percepção sobre quadro político

Tópico 2 - conhecendo o eleitor - influências

Tópico 3 - demandas e expectativas do eleitor

Tópico 4 - imagem da candidata

Desta forma, o tópico primeiro desta pesquisa abarcou as seguintes questões: a visão sobre a política e os políticos de uma maneira geral; conhecimento e percepção do eleitor capixaba sobre seus representantes no legislativo federal.

O segundo tópico tratou das influências que pesam sobre a decisão do voto do eleitor. Uma questão específica sobre formas de aproximação do candidato com os eleitores foi acrescida. Isso porque entendemos que as eleições são também um fórum comunicativo, que exige de seus atores um esforço de aproximação com seu público, no caso, os eleitores. O objetivo desta questão foi levantar informações que pudessem auxiliar as estratégias de comunicação da campanha. Outra questão debatida ainda no segundo tópico foi sobre a importância do partido e das alianças políticas na escolha dos candidatos. $O$ interesse aqui foi medir o conhecimento que o grupo detinha do sistema político-eleitoral e sua influência sobre os resultados das eleições, uma vez que as eleições para deputados federais e deputados estaduais são proporcionais ${ }^{1}$. Essa característica do sistema eleitoral brasileiro dá aos partidos políticos um peso considerável no processo eleitoral e faz com que as alianças e coligações sejam fundamentais para eleição de candidatos à Câmara Federal e às assembleias estaduais.

O terceiro tópico reuniu questões relacionadas às demandas do eleitor e às motivações que fundamentam sua decisão de voto, além dos assuntos que consideram importantes de serem levados ao Congresso Nacional. O objetivo era estimular os participantes a comentar e apontar os problemas sociais que deveriam ser priorizado nas pautas dos candidatos.

O quarto tópico foi dedicado à avaliação da imagem, propostas e atuação dos parlamentares capixabas na Câmara Federal e da deputada federal Iriny Lopes, em especial.

\footnotetext{
${ }^{1}$ Para que um candidato seja eleito, é preciso que o partido ou coligação partidária a que ele pertence tenha obtido o chamado quociente eleitoral, que é obtido pela divisão do total de votos válidos apurados pelo número de vagas em disputa $<\mathrm{http}$ ://www.jurisway.org.br/v2/pergunta.asp?idmodelo=8459>; acesso em $25 / 01 / 2012$.
} 
É claro que num debate aberto, questões que seriam tratadas em um tópico específico, podem surgir em tópicos anteriores na fala espontânea dos participantes, e aí mesmo devem ser exploradas, aproveitando a discussão que surge. Isso significa que o moderador (que pode ser o próprio pesquisador ou um especialista em técnica de entrevistas) tem liberdade diante do roteiro para mudar sua ordem de acordo com a dinâmica que se estabelece entre os participantes. Evidentemente, ele deverá estar atento para que todos os tópicos (e as questões neles contidas) sejam explorados ao longo da conversação. Além disso, é comum surgir na discussão questões que não estavam previstas no roteiro e que se mostram pertinentes para o tema em foco, de acordo com a importância que lhes é dada pelo grupo.

\section{V.2 A seleção dos participantes}

Como já colocado anteriormente, o artigo relata uma pesquisa experimental realizada como parte do aprendizado de alunos de comunicação social nas técnicas de pesquisa em comunicação. Em função disso, algumas regras próprias de grupos de discussão tiveram que ser quebradas, principalmente devido ao tempo para realização da atividade. Além deter sido feita apenas uma entrevista, o que sabidamente não é suficiente para os resultados de uma pesquisa para um cliente real, a composição do grupo ficou por demais heterogênea. Havia uma diferença muito grande entre a idade dos componentes - entre 22 e 60 anos - e na renda mensal que variava entre 620 reais e dez mil reais. Pela regra, cada reunião de grupo focal deve reunir pessoas que tenham um perfil socioeconômico e etário aproximados. Mesmo cientes de tais procedimentos e das visões muito diferenciadas que poderiam se manifestar pela heterogeneidade do grupo, consideramos que a experiência seria válida para o teste prático da técnica no ambiente acadêmico. Tais considerações foram feitas anteriormente em sala de aula.

De acordo com a literatura, o número de participantes para a realização de grupo de discussão varia de cinco a doze pessoas ${ }^{2}$. 0 grupo foi formado por sete pessoas; uma aposentada e uma educadora social moradoras de comunidades carentes, uma empresária do setor de importação e exportação, um agente dos Correios com atuação ativa no sindicato da categoria, dois estudantes universitários e uma consultora de Marketing com histórico de atuação no movimento estudantil. Todos os

\footnotetext{
${ }^{2}$ Barros Filho e Thornton falam entre cinco a doze participantes; Barros e Duarte, entre oito e doze; e Gaskell, entre seis e doze.
} 
participantes eram eleitores no Espírito Santo, moradores de municípios da Região Metropolitana da Grande Vitória. Garantiu-se ainda que os selecionados não fossem filiados a partidos políticos ou vinculados a alguma campanha para que nenhum outro interesse, que não fossem dos objetivos traçados, pudessem contaminar os resultados da pesquisa.

Nenhum dos participantes recebeu ajuda de custo. O grupo foi selecionado entre pessoas conhecidas de outros professores do curso de Comunicação da Faculdade Novo Milênio, mas não conhecidos entre si. Vale ressaltar que os professores que ajudaram na seleção, não participaram da reunião, o que garantiu o anonimato do grupo, fator importante para evitar que influências externas ao tema possam contaminar o debate com questões alheias ao objetivo da pesquisa.

A reunião foi iniciada às 9 h40, no centro de Vitória-ES. Estavam presentes os sete participantes convidados a formar o grupo de discussão e a moderadora (que foi também a responsável pela pesquisa), que se posicionaram formando um círculo. Além desses, estavam presentes na sala, mas recuados em relação ao grupo, uma documentadora (responsável pelos apontamentos por escrito) e um cinegrafista para registro audiovisual. o audiovisual serviu depois como material de aula, quando a dinâmica e os resultados da pesquisa foram apresentados e debatidos com os alunos. A reunião teve cerca de duas horas de duração, além do tempo despendido nas conversas mantidas separadamente com cada participante sobre as impressões causadas pela dinâmica. $O$ tempo total da atividade girou em torno de duas horas e meia.

Antes de iniciar a dinâmica, foi pedido aos participantes que respondessem a um questionário fechado, onde deveriam informar se teriam ou não simpatia por algum partido e sobre já ter ou não candidato definido para presidente, governador, senador e deputado federal. Eles assim se manifestaram:

\begin{tabular}{l|l|l|l|l|l}
\hline \multirow{2}{*}{ Participante } & $\begin{array}{l}\text { Simpatia } \\
\text { por } \\
\text { partido }\end{array}$ & \multicolumn{4}{|l|}{ Candidatos } \\
\cline { 2 - 6 } & Partido & Presidente & Governador & Senador & $\begin{array}{l}\text { Deputado } \\
\text { federal }\end{array}$ \\
\hline MRBO & Não & Serra & Não & Não & Não \\
\hline LISBOA & PSDB & Serra & Luiz Paulo & Não & Não \\
\hline SAB & PCdoB e PT & Marina & Não & Não & Não \\
\hline FMM & PT & Dilma & Casagrande & Ferraço & Não \\
\hline
\end{tabular}




\begin{tabular}{l|l|l|l|l|l}
\hline MGA & Não & Não & Não & Não & Não \\
\hline RGN & Não & Marina & Não & Não & Não \\
\hline VND & Não & Não & Não & Não & Não \\
\hline
\end{tabular}

O objetivo deste questionário foi levantar dados preliminares que apontassem o perfil político- ideológico dos participantes, o que permitiria entender melhor seus posicionamentos e como estes teriam consequências sobre suas opiniões e decisões.

\section{Resultados da pesquisa}

Apresentamos, em seguida, a análise dos resultados, que se deu sobre o conteúdo das falas dos participantes - como será visto ao longo do relato da pesquisa. Poderemos observar claramente como o mundo de vida dos participantes se manifesta em suas falas, especialmente por meio das influências que eles apontam como importantes na formação das opiniões e posições políticas. Isso pode ser observado por meio de uma leitura horizontal, feita a partir dos comentários, argumentos e pontos de vistas divergentes e convergentes manifestados ao longo dos temas colocados em discussão (MYERS, 2005).

Outro aspecto que transpareceu das falas, e que de alguma maneira era esperado em função da heterogeneidade do grupo, é que as demandas levantadas pelos participantes estão claramente relacionadas às realidades de cada participante. As palavras ditas e as sugestões dadas revelaram as experiências de vida dos participantes e como estas apontam para os anseios de cada um em relação à política e à eleição.

A análise poderá ser compreendida de forma mais satisfatória na apresentação dos resultados da entrevista sobre as questões debatidas e que são relatados em seguida na ordem em que foram discutidos pelo grupo.

\section{VI.1 Tópico 1 - o quadro político}

O tópico foi iniciado com a seguinte questão: qual a ideia que a palavra "política" traz a sua mente? O objetivo da pergunta foi aproximar os participantes do tema da pesquisa, mas trouxe também as primeiras percepções e críticas acerca da forma como a política é praticada no Brasil e sobre imagem do político brasileiro em geral. Os 
primeiros a se manifestar preocupam-se inicialmente em explicar a função pública da política e do político.

É administração, gestão pública da cidade, da sociedade (...). A graça da política é como ela pode ser construída para resolução de conflitos, administração do interesse comum. Não acredito em sociedade sem política (LSB, 23 anos, estudante universitário).

[O político é] uma pessoa pública que é representante do povo (SAB, 24 anos, consultora de marketing).

Naturalmente, a discussão passa a ser a qualidade da política que é praticada no país. As falas apontam decepção, descrédito e aparente desinteresse pela política e pelos políticos de maneira geral. Surge um consenso em torno de uma imagem negativa dos políticos brasileiros, expresso em palavras como vergonha, aversão, corrupção, roubo, todas elas expressões de valor negativo. Os políticos aparecem como empecilho à prática da boa política.

Os politicos apodreceram essa coisa bonita que é a política. Tudo é política. Na nossa casa, com os nossos filhos. Aí eu sinto uma frustração enorme (VND, 60 anos, aposentada).

Uma coisa chata. Fui criado para não gostar disso, para não ter pensamento nenhum sobre isso, que político é tudo corrupto, que só se dá bem e a gente se ferra (MRBO, 22 anos, estudante universitário).

É roubo! Se um político aparecer hoje na minha casa, não será bem recebido. É aquele que promete e não cumpre. (...) Eu tenho vergonha da política (MGN, 36 anos, educadora social).

[Eu sinto] aversão. Eu me lembro que quando se falava em política na família, era uma coisa que não interessava. Os políticos eram sempre os mesmos, sempre governando em causa própria, corrupção. A aversão vem daí (RGN, 47 anos, empresária).

É interessante observar que já a partir da primeira pergunta se explicita a família como influência primeira na formação da opinião dos participantes. É importante que o moderador esteja atento às colocações que surgem espontaneamente no calor do debate. 0 que se poderá inferir da fala espontânea é o valor que o participante atribui a uma questão, que nem se quer havia sido colocada em discussão, pelo menos não até aquele momento. Isso mostra também a liberdade que o próprio grupo tem em sugerir o rumo da conversação para questões que lhe interessam. Cabe ao moderador estimular o debate sobre o ponto levantado, mas sem deixar que a conversa fuja aos objetivos da pesquisa. 
No ponto em que o grupo foi solicitado a citar nomes de deputados federais capixabas, os únicos lembrados foram os de Rita Camata (PMDB) e Luiz Paulo Veloso Lucas (PSDB), além dos senadores Renato Casagrande (PSB) e Magno Malta (PR). Um dado interessante que aparece na fala do grupo é a importância dos meios de comunicação para informação sobre a política. Os participantes justificaram a lembrança destes poucos nomes por serem de parlamentares a quem eles atribuíram forte presença na mídia local e nacional. o grupo considerou que a visibilidade política tem a ver com a exposição nos meios de comunicação, como ficou exemplificado na fala de um dos participantes: Casagrande sempre aparece na televisão. Magno Malta também (FMM, 30 anos, agente de correios). Neste momento da reunião, ninguém do grupo apontou ou sugeriu outros meios ou maneiras dos políticos se aproximarem dos cidadãos que os representam, que não a mídia.

Com poucos nomes citados, os participantes foram instados a lembrar em quem haviam votado na última eleição para deputado federal. Três deles disseram ter anulado o voto ou votado em branco, dois não lembraram e dois outros votaram na legenda do PT. Isso pode mostrar uma diversidade do grupo na forma de decidir e de certa forma justifica o desconhecimento dos participantes sobre os parlamentares capixabas, na mediada em que eles não fizeram uma escolha nominal, esqueceram seus candidatos ou não se interessaram em escolher um.

\section{VI.2 Tópico 2 - conhecendo o eleitor}

As discussões sobre os principais fatores de influência na decisão do voto se iniciaram já no tópico primeiro, postas espontaneamente pelo grupo, como desdobramento do debate anterior. Se ali, os meios de comunicação aparecem como importantes espaços de visibilidade do político, por outro lado são também eles que reforçam a imagem negativa da política.

Eu vivenciei toda aquela história de inflação, de Collor, de impeachment. Foram minhas primeiras impressões [da política]. Eu via meu avô discutindo, passava no Jornal Nacional (SAB).

Pode ser até que as pessoas que estão lá [na política] estão fazendo alguma coisa. Mas a gente não sabe. [A mídia] dá essa impressão que eles não estão fazendo nada. E meus pais também me passaram isso (MRBO).

As falas acima reforçam o papel dos meios de comunicação, sobretudo, a televisão, como importantes fontes de informação política, não só para fixação da imagem pública do político, mas 
também como meio de informação das plataformas e propostas dos candidatos.

Acho importante [participar das] entrevistas e debates na mídia como forma de conhecer as propostas do candidato e fazer a escolha do voto(RGN).

Eu assisto a todas as entrevistas [no período eleitoral] (VND).

Ao observar a importância dada pelos participantes aos meios de comunicação, fica claro que eles se referem aos meios tradicionais e, sobretudo, à televisão. Quando instados a comentar o papel das redes sociais na internet nas campanhas eleitorais, o grupo considerou que ainda é cedo para que estas sejam instrumentos eficazes na propaganda política. Só um participante discordou desta posição e viu nas redes sociais ferramentas de aproximação entre o candidato e o eleitor.

Poderia muito bem servir para construção conjunta de propostas para serem levadas à Câmara Federal. Tem que ter troca. É por isso que acredito tanto na política 2.0. Um candidato que fizer isso pode ganhar meu voto (SAB).

Os demais participantes se mostraram reticentes quanto à força que tais meios poderiam ter na campanha eleitoral de 2010 .

Eu também participo de redes sociais, mas acho que aqui não vai acontecer o mesmo que nos Estado Unidos, com o Obama. Ele foi um fenômeno no uso das redes. Mas aqui as pessoas aderem às redes por aderirem. Por isso que o Brasil é o país com maior número de pessoas no Orkut e daqui a pouco passa os Estados Unidos em número de usuários do Twitter. Mas ninguém se sente próximo de ninguém. As pessoas não têm um objetivo claro, é só um contato superficial (LSB).

Duas das participantes, moradoras de bairros periféricos, disseram que no lugar onde moram, as pessoas têm pouco acesso à internet. Mesmo quando outros participantes citaram as lan houses, comuns em bairros populares no Brasil, como ponto de acesso à internet, elas mostraram-se céticas.

Acho que lá as pessoas não dariam bola para isso (MGN).

Essa rede social para mim é nada. Não funciona. (VND).

É importante aqui uma consideração. Como a pesquisa foi realizada ainda na fase inicial da campanha eleitoral, não poderíamos discutir o papel que redes sociais tiveram nas campanhas dos candidatos. 
Para isso, seria necessária uma nova pesquisa numa fase intermediária ou mesmo final do período de eleição.

A discussão anterior antecipou o debate sobre que outras formas de contato e conhecimento seriam interessantes que os candidatos estabelecessem com os eleitores. Foi interessante observar que as opiniões foram relatadas em forma de lembranças e experiências pessoais dos participantes.

\begin{abstract}
Eu só vim a ter contato com política quando entrei no serviço público. 0 contato com o pessoal do meu sindicato trouxe esse interesse. Foi ali que aprendi que a política é um meio de administrar e que a gente faz parte desse processo e pode intervir (FMM).

Uma vez quando eu estava na escola, um prefeito de Vitória apareceu lá para falar com os estudantes. Eu lembro bem disso, apesar de não lembrar o nome dele. Achei importante. E eu nem tinha idade para $\operatorname{votar}(\mathrm{MRBO})$.
\end{abstract}

Nas falas acima e nas seguintes fica evidente que os participantes apontam os espaços de convivência em que estão inseridos - sejam as entidades coletivas e representativas, seja a escola e a comunidade - não só como os fóruns ideais a esta aproximação, mas também como locais de formação ideológica.

Na eleição passada, eu estava entrando na UFES (Universidade Federal do Espírito Santo) e participei do DCE. Eu votei na Heloísa Helena (...) as discussões ideológicas que ali aconteciam me influenciaram (LSB).

Eu me formei ideologicamente pelo $P C d o B$, no movimento estudantil. (SAB).

Paradoxalmente à importância que o grupo deu aos meios de comunicação, no desdobramento desta discussão, foi ficando claro que os participantes consideram o contato direto como fundamental para a comunicação entre o candidato e o eleitor. A conclusão é que na disputa eleitoral, principalmente aos cargos legislativos, o eleitor quer ser ouvido, ter algum protagonismo, e não ser apenas um ouvinte passivo.

Acho que eles [candidatos] deveriam ir às faculdades, às escolas, e ter encontros com os estudantes, trocar de ideias, exporem suas propostas. [O candidato] tem que estar aberto ao debate, tem que saber ouvir. Eu quero colaborar, quero me comunicar. Acho que o político não quer ouvir. Ele só quer ser ouvido (SAB).

O grupo também apontou a importância do político manter contato com o eleitor fora do período de eleição, não só como forma de se 
fazer conhecer, mas ainda para evitar a imagem de que a política é um jogo de interesse pessoal.

Não adianta vir só em época de eleição. Tem que vir sempre, se preocupar sempre (VND).

Voltando ao tema das influências, o grupo foi perguntado sobre a importância dos partidos e das coligações para a escolha dos candidatos. O que se percebe na fala de parte do grupo é que o partido é importante, mas a pessoa (candidato) é ainda mais. Alguns afirmaram não dar importância à filiação partidária. Neste momento da discussão, os participantes já revelam critérios que vão pesar na escolha dos candidatos.

A gente vota pela posição, pela proposta, pelo histórico dele. E não necessariamente pelo partido (RGN).

A mesma posição de falta de compromisso partidário aparece na fala de outros participantes, mesmo daqueles que no questionário apontaram simpatia por algum partido.

Não sou fiel a partido. Eu poderia mudar meu voto a cada eleição, em função dos interesses que tenho para a minha vida (LSB).

o meu candidato é aquele que vai agir pelo bem comum. Eu não me importo em perder voto, eu me importo em votar bem. (VND)

Apenas dois participantes, talvez por manterem envolvimento com entidades representativas que estão historicamente mais sujeitos a influências partidárias, como movimento estudantil e sindicato, têm nos partidos políticos referências capazes de influir sobre suas escolhas.

A proposta ideológica do PT está mais próxima de que eu entendo como a melhor forma de resolver aquilo que para mim são coisas prioritárias. Eu posso até não votar num candidato do PT, mas tem que ser da coligação (FMM).

Votar na coligação é uma decisão coerente, é saber votar. Porque se eu vou votar num presidente, governador, tenho que votar em quem está alinhado com ele. Pois o deputado é quem propõe e aprova os projetos de governo. É ele quem faz a ligação entre o governo federal e o estadual (SAB). 


\section{VI.3 Tópico 3 - demandas e expectativas}

Neste tópico, buscou-se conhecer as questões sociais e políticas que mobilizam os participantes para uma tomada de decisão. 0 objetivo foi desvendar as razões de suas escolhas eleitorais. O grupo foi estimulado a expor suas demandas e opinar sobre quais seriam os principais assuntos que deveriam ser levados à Câmara Federal.

Num primeiro instante, a fala do grupo se localizou nas demandas individuais e interesses específicos, inclusive em forma de queixa.

Eu voto em branco. A politica em Vila Velha é zero. Hoje eu preciso de um neurologista e não tenho dentro do município. Então vou votar para que? Em quem? (MGN).

o problema do preconceito [contra o homossexual]. Ninguém quer modificar isso. Eu votaria em alguém que tratasse disso. No [senador] Magno Malta eu não voto porque ele defende a família [tradicional] (MRBO).

o que vai diferenciar o candidato do partido que defende questões sociais são as minorias. O que vai fazer diferença vai ser aquele candidato que tiver discurso em prol das minorias, lembrar do pobre, lembrar do negro, do homossexual. (FMM).

O trabalho social é o que me move também na [escolha] política. 0 trabalho social pode mudar a vida de muitas pessoas. (VND)

Nas falas seguintes são tratadas questões mais abrangentes e começam a surgir os consensos entre os participantes. $O$ destaque aí para a saúde e educação, não só a formal, mas também a educação para o trabalho.

Eu ficaria com vontade em votar em candidato que tivesse preocupações com a educação, mas não a educação de construir escola, mas na formação, na qualificação. Acho que investir na educação resolveria todos os nossos problemas lá na frente (RGN).

Eu também voto pela qualificação das pessoas (LSB). Acho importante investir em educação. Educação é a única chance para tudo. (FMM).

o que me seduz mesmo é ver meu povo deixar a exclusão pelo ensino e pela saúde. A saúde é uma questão urgente. (VND)

Um dado curioso é que quando perguntado sobre que questões deveriam estar na pauta dos deputados federais eleitos pelo Espírito Santo, os participantes levantaram não necessariamente questões relacionada às demandas que eles haviam apontados na discussão anterior. O que sobressai na fala do grupo é o problema da autoestima do capixaba, que foi relacionado à baixa representatividade do estado em nível nacional. 
A visão que se tem é que o Espírito Santo só serve para aumentar a distância entre Rio e Bahia (FMM).

Em seguida, começaram a aparecer questões mais pontuais, relacionadas ao que os participantes consideram entraves ao desenvolvimento do estado e que devem ser enfrentadas como prioritárias. O curioso é que de todas as falas, apenas uma participante alinhou os interesses do estado às demandas manifestadas anteriormente.

Trabalhar a educação, tornar a educação capixaba competitiva a nível nacional (RGN).

Os demais apontam demandas específicas, voltadas aos problemas do estado.

Tem que concluir o aeroporto e [melhorar] a infraestrutura de um modo geral (LSB).

O sistema portuário do estado estagnou. Outros portos do país tiveram grandes investimentos e nós não. As empresas daqui estão mandando [seus produtos] para outros portos. No porto de Vitória só entra navio pequeno. (RGN)

Neste momento da discussão, os participantes foram estimulados a discutir que qualidades o candidato deve possuir e defeitos que não pode ter. Além do comportamento ético considerado importante, como se percebe pela expressão de valores como honestidade, humildade, probidade, o grupo novamente aponta para o problema da falta de informações sobre seus representantes, já manifestado no primeiro tópico. O desconhecimento sobre o histórico de sua atuação é, para o grupo, um empecilho à reeleição de um candidato. Ao mesmo tempo, nenhum participante do grupo mostrou conhecimento sobre propostas de candidatos a deputado federal. Isso pode ter sido motivado pelo fato da entrevista ter sido realizada no início do período da campanha eleitoral, o que pode explicar o fato de todos responderem ainda não ter candidato para este cargo.

Não votaria nulo hoje, mas não tenho candidato nem informação sobre eles. Ainda vou me informar (LSB).

As falas seguintes são reveladoras da importância que os participantes dão ao histórico do candidato, ao mesmo tempo em que mostram a importância da visibilidade política. 
A plataforma política deles e o que eu já conheço deles é que vai fazer eu me decidir. 0 passado deles é que vai me revelar, me dar uma visão deles. E ele tem que ser ético, honesto e preocupado com a inclusão social (VND).

Não voto em quem está lá [no Congresso Nacional] há muito tempo, pois se ele não se projetou, se não sabemos nada sobre ele é porque não faz nada. Isso é defeito (SAB).

Um defeito é a gente não saber da história dele. A qualidade é saber quem ele é, o que faz (MGN).

A percepção do grupo sobre uma suposta falta de transparência na atuação dos parlamentares reforça a visão negativada política. A fala de uma participante ilustra o desencantamento do grupo com os políticos brasileiros ao mesmo tempo em que mostra um anseio por mais qualidade no exercício da política no Brasil.

Eu não gostaria de votar em branco novamente. Gostaria de ter candidato $(\mathrm{MGN})$.

\section{VI.4 Tópico 4 - a imagem da deputada federal Iriny Lopes}

O tópico final foi construído para atender ao objetivo da pesquisa no que diz respeito à candidata à reeleição Iriny Lopes. A primeira questão serviu para verificar o nível de conhecimento dos participantes sobre a candidata e também para avaliar sua imagem e sua atuação como parlamentar junto ao grupo. Assim, o tópico foi iniciado com a seguinte pergunta: vocês conhecem a deputada federal Iriny Lopes? O que surgiu daí foram informações senão confusas, ao menos controversas, que de certa forma revelaram o pouco conhecimento do grupo sobre a candidata.

É interessante inferir, nas falas seguintes, a importância que os participantes novamente atribuem à visibilidade política para o conhecimento não só do candidato, mas mesmo do parlamentar.

Sei que é um nome forte [de destaque], mas não conheço, não tenho nenhuma informação sobre ela. Só conheço aquilo que aparece (MRBO).

A falta de mais informação acerca da candidata motiva a controvérsia que surge em torno de seu nome, quando uma participante lança uma suspeita em relação a sua conduta parlamentar. Deste ponto, começam a surgir algumas impressões sobre a deputada Iriny Lopes. 
Eu fiquei com uma dúvida com relação a uma notícia ligada à coisa ruim. Foi ela ou não que foi denunciada por uso de carro oficial por familiares dela, num fim de semana? Acho que eles estavam com o carro num posto de gasolina tomando cerveja (RGN).

A suspeita é rebatida por duas outras participantes, de que não se tratava da deputada Iriny Lopes, mas de uma deputada estadual. 0 caso relatado não se deu de fato com Iriny Lopes, mas sim com uma deputada estadual, flagrada com familiares no carro oficial e próxima a um bar. O problema é que a suspeita entre outros participantes não se dissipa

A partir da dúvida inicial, a figura da deputada começa a ganhar mais nitidez entre os participantes, que reconhecem nela uma parlamentar com forte atuação partidária, o que não é visto necessariamente como dado positivo.

Quando penso no PT capixaba, os nomes que logo me vêm à mente são os de Iriny e Perly Cipriano. Acho que ela tem força excessiva [no sentido também de atuação política] (FMM).

Ela é forte partidariamente, mas ela é fraca de representatividade [atuação parlamentar] (SAB).

Talvez ela seja muito forte no partido. Talvez fosse melhor desvincular um pouco sua imagem do PT (RNG).

Eu a vejo como petista, com forte imagem partidária (LSB).

A postura física da candidata também mereceu comentário.

Ela passa uma imagem de fragilidade, fisicamente falando... Postura física... Não mostra altivez (LSB).

Ela parece o Enéas, repetindo eu sou PT, PT, PT! Carrega uma identidade petista muito forte. Acho sinistro. Terninho vermelho, camisa branca com símbolo do PT. É uma imagem pesada, antiga, que ela traz na propaganda política. E ela pouco aparece nos veículos [de comunicação] locais. Tem que aparecer mais. Precisa deixar o lado humano aparecer e não essa coisa partidária. Parece que não tem ideologia ou imagem própria. (SAB)

Por outro, aqueles participantes que disseram já ter tido contato mais próximo com a candidata, guardam uma imagem dela como uma parlamentar atuante. 
Para mim, ela é mais humana [no sentido de um contato mais estreito com a população]. Tivemos um curso de formação para a educação na minha Congregação [Padre Xavier] e ela foi lá participar. Levou propostas para o Congresso e deu retorno. Nem sabia que ela era do PT. Lembro da pessoa (MGN).

Conheço pessoalmente e em reuniões na minha ordem religiosa. Foi um encontro realizado durante a campanha do Lula [para presidente em 2006] com a presença do Leonardo Boff. E conheço ela por causa do Cláudio Vereza (deputado estadual pelo PT). Eles fazem campanha juntos. Ela não aparece muito, mas quando aparece é importante (VND).

Mas apesar do conhecimento pessoal, a mensagem da deputada não se fixou na memória das participantes.

Não lembro o que ela falou, nem que propostas trouxe (MGN). Foi alguma coisa com a causa social. Não sei precisar. Mas se fosse coisa ruim, eu lembraria (VND).

As falas finais levam a duas interpretações. Primeiramente, a imagem da candidata é percebida de forma positiva no âmbito das entidades de classe ou comunitárias que são espaços de sua atuação. Por outro lado, isso não garante que sua mensagem seja lembrada com clareza mesmo por quem vê na atuação política da deputada convergência com seus interesses enquanto eleitor.

\section{Considerações finais}

Não pretendemos neste artigo definir ações estratégicas para a campanha de reeleição da deputada Iriny Lopes. A intenção antes foi relatar uma experiência de aprendizado acadêmico do curso de Comunicação Social da Faculdade Novo Milênio, de aplicação da técnica de grupo de discussão como exemplo de pesquisa com método qualitativo. A realização e registro da experiência resultaram ainda na produção de material didático -um audiovisual de um case de pesquisa em comunicação -, para uso em sala de aula.

A importância da experiência com a pesquisa qualitativa em grupo de discussão deu-se, sobretudo, pela constatação de que esta é uma técnica pouco conhecida e explorada por alunos do curso, mais afeitos ao método quantitativo com emprego de questionário ou ao método qualitativo com o emprego da técnica de entrevistas individuais. Assim, a dinâmica realizada serviu de aproximação dos alunos com a técnica de grupo de discussão, uma vez que eles participaram de todas as etapas de planejamento da pesquisa e depois tiveram oportunidade de assistir e discutir a experiência em 
sala. Foi durante as aulas da disciplina de Pesquisa em Comunicação e Análise de Mercado que os objetivos da pesquisa foram levantados, os procedimentos empreendidos e pensados e as limitações impostas, discutidas e esclarecidas.

O foco dado às campanhas eleitorais permitiu ainda demonstrar a natureza da informação que se pode obter nos grupos de discussão e, no caso deste relato, sua contribuição ao planejamento de marketing para fins eleitorais, momento em que são traçadas as estratégias que vão definir o posicionamento e a comunicação do candidato junto aos eleitores. Neste sentido, algumas pontuações podem ser feitas a partir do que foi dito e discutido pelo grupo em análise. A questão da comunicação do candidato é um ponto que aparece como importante e que deve ser considerado no que diz respeito à imagem e conhecimento do político e/ou candidato. No caso da campanha para a reeleição da deputada federal Iriny Lopes, a comunicação apareceu no grupo como um problema, o que é demonstrado pela pouca informação que os participantes detêm sobre sua atuação parlamentar e na não fixação de sua mensagem política por aqueles que tiveram com ela contato pessoal. Naquele momento, a pesquisa apontou que deveria haver um maior reforço de mídia no intuito de aumentar o grau de conhecimento das pessoas em relação à atuação parlamentar de Iriny Lopes, que então pleiteava um terceiro mandato.

As falas do grupo revelaram também que a chamada mídia tradicional era naquele momento ainda a maior fonte de informação e de conhecimento da atuação parlamentar, sobretudo e ainda a televisão. O grupo não considerou as redes sociais como eficazes na comunicação entre candidato e eleitor. Pelo contrário, houve mais crítica negativa do que aceitação na forma como a propaganda eleitoral é apresentada nos meios digitais. Esse é um dado significativo para o planejamento de marketing, que provavelmente teria que investir o maior esforço de comunicação do candidato em programas da televisão aberta, ainda a maior força de mídia na visão dos participantes, como fica claro pelos programas de TV citados pelo grupo.

O desconhecimento dos participantes em relação à atuação da candidata enquanto deputada se reforçou pelas questões que o grupo apontou como demandas a serem atendidas e os assuntos considerados prioritários para inclusão na plataforma de um candidato a deputado federal. Questões como direitos das minorias, a infraestrutura portuária e aeroportuária, a educação para o trabalho, a valorização da cultura local, são temas da pauta política de deputada, não reconhecida pelo grupo, sequer pelas duas participantes que tiveram contato pessoal com ela em eventos 
políticos. A lembrança ficou vaga. Não houve clareza sobre quem é e como atua a deputada federal Iriny Lopes.

A percepção mais clara sobre Iriny Lopes manifestada pelo grupo foi de uma forte imagem partidária. Nas falas do grupo, ficou claro, por um lado, que a vinculação política não é necessariamente decisiva na escolha do eleitor, podendo até ser uma desvantagem, na medida em que ele está mais interessado em propostas do candidato do que no compromisso partidário. O forte vínculo partidário apontado pelos participantes na mensagem da candidata mostrou mais desgaste de imagem do que vantagem política. Talvez este fato possa estar relacionado com o comportamento do eleitor capixaba em eleições anteriores, em que o partido da deputada tem sido suplantado por outras siglas e alianças. Mas esta questão não coube discutir aqui, pois o artigo tratou de abordagem metodológica e não teórica sobre os resultados obtidos na experiência de pesquisa. Mas a questão política seria uma abordagem possível de ser realizada com base nas informações trazidas e nos temas debatidos pelo grupo selecionado.

Outro aspecto que a dinâmica permitiu perceber foi como se forma a decisão do voto na mente do eleitor. Essa percepção se torna clara nas opiniões e nas discussões acerca do cenário político local e nacional, bem como os fatores de influência a que os participantes estão sujeitos, com base nas suas experiências de vida e no contexto social e cultural em que estão inseridos. Ou seja, a experiência do mundo de vida que prevalece nas palavras e opiniões de participantes em grupos de discussão.

\section{Referências}

BARROS FILHO, Clóvis; THORNTON, Ricardo. Política e opinião: dos números às letras _ in: Comunicação na polis: ensaios sobre mídia e política. Clóvis de Barros Filhos (org.). Petrópolis, Editora Vozes, 2003, p.247-268.

GASKELL, George. Entrevistas individuais e grupais - in: Pesquisa qualitativa com texto imagem e som: um manual prático. Martin W. Bauer e George Gaskell (Org.). 4ª edição, Petrópolis, Editora Vozes, 2005, p. 64-89.

VEIGA, Luciana. GONDIM, Sônia Maria Guedes. A utilização do método quantitativo na ciência política e no marketing político. Opinião pública, maio /volume VII, número 001, Universidade Estadual de Campinas, São Paulo, 2001, pp. $1-15$. 
MYERS, Greg. Análise da conversação e da fala - in: Pesquisa qualitativa com texto imagem e som: um manual prático. Martin W. Bauer e George Gaskell (Org.). $4^{\mathrm{a}}$ edição, Petrópolis, Editora Vozes, 2005, p. 271-292.

PINHO, J. B.. Comunicação em marketing: princípios de comunicação mercadológica 5 a edição, Campinas, Papirus Editora, 2001.

TELLES. Helcimara de Souza.Eleitores Voláteis, Eleitores Petistas: que samba isso dá em Beagá? 2008.

VAZ, Gil Nuno. Marketing institucional. 3ª ed., São Paulo, Editora Thomson, 2003.

A Revista Compolítica é uma revista eletrônica da Associação Brasileira de Pesquisadores em Comunicação e Política. Com periodicidade semestral, sua proposta é difundir a produção acadêmica relacionada às interfaces desses campos de estudo. 